\title{
Variable Viscosity and Thermal Conductivity on Convective Heat Transfer in a Dusty Fluid over a Vertical Permeable Surface with Radiation and Viscous Dissipation
}

\author{
G.C. Hazarika \\ Department of Mathematics \\ Dibrugarh University \\ Dibrugarh, Assam, India.
}

\begin{abstract}
The effects variable viscosity and thermal conductivity on a steady free convective boundary layer flow of a dusty fluid past a vertical permeable stretching surface with viscous dissipation and thermal radiation is studied. The system of partial differential equations together with the prescribed boundary conditions governing the equations of motion are reduced to a system of ordinary differential equations using similarity transformations. The resultant boundary value problems are then solved numerically using shooting technique based on fourth order Runge-Kutta method. The effects of physical parameters viz., viscosity parameter, thermal conductivity parameter, fluid-particle interaction parameter, local Grashof number, suction parameter, Prandtl number, radiation parameter and Eckert number on the flow and heat transfer are computed and presented graphically. The temperature gradient which gives the rate of heat transfer at the surface and skin friction coefficient are also obtained and present in Tables. The effects of all the parameters are quite significant.
\end{abstract}

\section{Keywords}

Variable viscosity and thermal conductivity, Dusty fluid; fluid-particle interaction parameter; radiation parameter; viscous dissipation

\section{INTRODUCTION}

Due to application in industry and in technology the study of flow and heat transfer over a stretching sheet has drawn the interest of many researchers. It takes very important role in industries such as chemical industry, power and cooling industry for drying, chemical vapour deposition on surfaces and cooling of nuclear reactors etc. Such processes occur when the effect of buoyancy forces in free convection becomes significant. The problem of free convection under the influence of magnetic field has attracted numerous researchers in view of its applications in geophysics and astrophysics. Many problems of flow and convective heat transfer over a stretching sheet and stretching surfaces have been studied for both Newtonian and non-Newtonian fluids with applied electric and magnetic fields, under different thermal boundary conditions. Crane [1] first studied the problem of steady two-dimensional boundary layer flow of an incompressible and viscous fluid caused by a stretching sheet. Grubka and Bobba [2] studied the heat transfer effects by considering the power-law variation of surface temperature.
The flow and heat transfer over a vertical stretching sheet under various physical situations have been reported by many researchers like Daskalakis [3], Chen [4], Chamkha [5], Ishak et al. [6], Saleh et al. [7], Gireesha et al. [8]. Kumari et al. [9] have studied the unsteady free convection flow over a continuous moving vertical surface in an ambient fluid by taking two different heating processes like constant surface temperature (CST) and constant surface heat flux (CHF). Chakrabarti [10] studied the boundary layer flow of a dusty gas. Datta and Mishra [11] have investigated boundary layer flow of a dusty fluid over a semi-infinite flat plate. Several investigators such as Agranat [12], Vajravelu et al. [13], Evgeny et al. [14], XIE Ming-liang et al. [15] and Palani et al. [16] studied flow problems of dusty fluids. Gireesha et al. [17] obtained the numerical solution for boundary layer flow and heat transfer of a dusty fluid over a stretching sheet with nonuniform heat source/sink. The above investigations deal with the flow and heat transfer induced by a horizontal stretching sheet, but there arise some situations where the stretching sheet moves vertically in a cooling liquid. Under such circumstances the fluid flow and the heat transfer characteristics are determined by two mechanisms, namely motion of the stretching sheet and the buoyant force. Also, in the above studies, the radiation effect was ignored. But, in the systems operating at high temperatures, the thermal radiation heat transfer becomes very important and its effects cannot be neglected. Thermal radiation $t$ plays a significant role in controlling heat transfer processes in polymer industry.

Chen [18] analyzed MHD mixed convection of a power law fluid past a stretching surface in the presence of thermal radiation and internal heat generation/absorption. Mukhopadhyay and Layek [19] studied free convective flow and radiative heat transfer of a viscous incompressible fluid with variable viscosity over a stretching porous vertical plate. Ramesh et al.[20] studied the effects of thermal radiation on a steady boundary layer flow and heat transfer of an incompressible viscous dusty fluid over a permeable vertical stretching surface.

In all the earlier investigations viscosity and thermal conductivity were assumed as constant. But viscosity and thermal conductivity varies with temperature. In this paper an attempt has been made to study numerically the effects of viscosity and thermal conductivity on flow and heat transfer of an incompressible viscous dusty fluid over a permeable vertical stretching surface with thermal radiation and viscous dissipation. The resulting non-linear boundary value problem in 
ordinary differential equations is solved by shooting technique based on fourth order Runge-Kutta method. Velocity and temperature distributions are presented in graphs for various flow characteristic parameters. The coefficient of skin friction and temperature gradient at the surface which is the rate of heat transfer are presented in tables. The effects of all the flow parameters are significant.

\section{FLOW ANALYSIS OF THE PROBLEM}

We consider a steady two dimensional laminar boundary layer flow of an incompressible viscous dusty fluid over a vertical stretching sheet. The flow is generated by the action of two equal and opposite forces along the $x$-axis and $y$-axis being normal to the flow. The sheet being stretched with a velocity $U_{w}(x)$ along the $x$-axis, keeping the origin fixed in the fluid of ambient temperature $T$.

The dust particles are assumed to be spherical in shape and uniform in size and number density of the dust particle is taken as a constant throughout the flow. With these assumptions and usual boundary layer approximations, and following Vajravelu and Nayfeh [6] we get the equations motions as :

$\frac{\partial u}{\partial x}+\frac{\partial v}{\partial y}=0$

$\mathrm{u} \frac{\partial u}{\partial x}+v \frac{\partial u}{\partial y}=\frac{\partial}{\partial y}\left(\mu \frac{\partial u}{\partial y}\right)+\frac{K N}{\rho}\left(u_{p}-u\right)+\mathrm{g} \beta^{*}\left(\mathrm{~T}-\mathrm{T}_{\infty}\right)$

$u_{p} \frac{\partial u_{p}}{\partial x}+v_{p} \frac{\partial u_{p}}{\partial y}=\frac{K}{m}\left(u-u_{p}\right)$

$u_{p} \frac{\partial v_{p}}{\partial x}+v_{p} \frac{\partial v_{p}}{\partial y}=\frac{K}{m}\left(v-v_{p}\right)$

$\frac{\partial}{\partial x}\left(\rho_{p} u_{p}\right)+\frac{\partial}{\partial y}\left(\rho_{p} v_{p}\right)=0$

where $(u, v)$ and $\left(u_{p}, v_{p}\right)$ are the velocity components of the fluid and dust particle phases along $x$ and $y$ directions respectively. $\mu, \rho, \rho_{p}$ and $N$ are the co-efficient of viscosity of the fluid, density of the fluid, density of the particle phase, number density of the particle phase respectively. $K$ is the stokes resistance (drag coefficient). $T$ and $T_{\infty}$ are the fluid temperature with in the boundary layer and in the free stream respectively. $g$ is the acceleration due to gravity, $\beta^{*}$ is the volumetric coefficient of thermal expansion, $m$ is the mass of the dust particle respectively. In deriving these equations, the drag force is considered for the interaction between the fluid and particle phases.

The dusty boundary layer heat transport equations with radiation are:

$\rho c_{p} \quad\left(\mathrm{u} \frac{\partial T}{\partial x}+v \frac{\partial T}{\partial y}\right)=\frac{\partial}{\partial y}\left(k \frac{\partial T}{\partial y}\right)+\frac{N c_{p}}{\tau_{T}}\left(T_{p}-T\right)+\frac{N}{\tau_{v}}\left(u_{p}-u\right)^{2}-$ $\frac{\partial q_{r}}{\partial y}+\mu\left(\frac{\partial u}{\partial y}\right)^{2}$

$u_{p} \frac{\partial T_{p}}{\partial x}+v_{p} \frac{\partial T_{p}}{\partial y}=-\frac{c_{p}}{c_{m} \tau_{T}}\left(T_{p}-T\right)$ where $T$ and $T_{p}$ is the temperature of the fluid and temperature of the dust particle, $c_{p}$ and $c_{m}$ are the specific heat of fluid and dust particles, $\tau_{T}$ is the thermal equilibrium time and is the time required by the dust cloud to adjust its temperature to the fluid, $\tau_{v}$ is the relaxation time of the of dust particle i.e., the time required by a dust particle to adjust its velocity relative to the fluid, $k$ is the thermal conductivity.

Using the Rosseland approximation for radiation [4], radiation heat flux is simplified as

$\mathrm{q}_{\mathrm{r}}=-\frac{4 \sigma^{*}}{3 k^{*}} \partial T^{4} / \partial y$

where $\sigma^{*}$ and $k^{*}$ are the Stefan-Boltzman constant and the mean absorption co-efficient respectively. The temperature differences within the flow is such that the term $T^{4}$ may be expressed as a linear function of the temperature. Expanding $T^{4}$ in a Taylor series about $T_{\infty}$ and neglecting the higher order terms beyond the first degree in $\left(T-T_{\infty}\right.$ we get

$\mathrm{T}^{4} \cong 4 \mathrm{~T}_{\infty}^{3} \mathrm{~T}-3 \mathrm{~T}_{\infty}^{4}$

Substituting equations (8) and (9) in (6) we get,

$\rho c_{p}\left(u \frac{\partial T}{\partial x}+v \frac{\partial T}{\partial y}\right)=\left(k+\frac{16 \sigma^{*} T_{\infty}^{3}}{3 k^{*}}\right) \frac{\partial^{2} \mathrm{~T}}{\partial y^{2}}+\frac{\partial k}{\partial y} \frac{\partial T}{\partial y}+\frac{N c_{p}}{\tau_{T}}\left(T_{p}-T\right)$

$+\frac{\mathrm{N}}{\tau_{\mathrm{v}}}\left(\mathrm{u}_{\mathrm{p}}-\mathrm{u}\right)^{2}+\mu\left(\frac{\partial u}{\partial y}\right)^{2}$

The boundary conditions for the flow problem are given by

$\mathrm{u}=\mathrm{U}_{\mathrm{W}}(\mathrm{x}), \mathrm{v}=-\mathrm{V}_{\mathrm{W}}(\mathrm{x}), \mathrm{T}=\mathrm{T}_{\omega}=\mathrm{T}_{\infty}+\mathrm{A}\left(\frac{\mathrm{x}}{\mathrm{l}}\right)^{2}$ at $\mathrm{y}=0$

$\mathrm{u} \rightarrow 0, \mathrm{up}_{\mathrm{p}} \rightarrow 0, \mathrm{vp} \rightarrow \mathrm{v}, \rho_{\mathrm{p}} \rightarrow \omega \rho, \mathrm{T} \rightarrow \mathrm{T}_{\infty}, \mathrm{T}_{\mathrm{p}} \rightarrow \mathrm{T}_{\infty}$

as $y \rightarrow \infty$

where $U_{w}(x)=c x$ is the stretching sheet velocity, $c>0$ is the stretching rate, $\omega$ is the density ratio, $T_{w}$ and $\mathrm{T}_{\infty}$ denote the temperature at the wall and at large distance from the wall respectively, $A$ is apositive constant and $l=\sqrt{\frac{v}{c}}$ is a characteristic length.

Following Lai and Kulacki [21] we assume that the viscosity and thermal conductivity are inverse linear functions of temperature, i.e.

$$
\begin{gathered}
\frac{1}{\mu}=\frac{1}{\mu_{\infty}}\left[1+\delta\left(T-T_{\infty}\right)\right], \text { or } \frac{1}{\mu}=a(T- \\
\operatorname{TC} \text { where } a=\delta \mu \infty \text { and } T_{C}=T \infty-1 \delta \\
\frac{1}{k}=\frac{1}{k_{\infty}}\left[1+\xi\left(T-T_{\infty}\right)\right], \text { or } \frac{1}{k}=b(T- \\
\operatorname{Tr} \text { where } b=\xi k \infty \text { and } \operatorname{Tr}=\operatorname{T} \infty-1 \xi
\end{gathered}
$$

Where $a, b, T_{c}$ and $T_{r}$ are constants and their values depend on the reference state and thermal properties of the fluid i.e. $v$ and k. In general $a, b>$ 0 for liquids and $a, b<0$ for gases. 
Let us introduce the following similarity transformations,

$$
\begin{aligned}
& \mathrm{u}=\operatorname{cx} \mathrm{f}^{\prime}(\eta), \mathrm{v}=-\sqrt{v c} \mathrm{f}(\eta), \eta=\sqrt{\frac{c}{v}} y \\
& \mathrm{u}_{\mathrm{p}}=\operatorname{cx} \mathrm{F}(\eta), \mathrm{v}_{\mathrm{p}}=\sqrt{v c} \mathrm{G}(\eta), \rho_{\mathrm{r}}=\mathrm{H}(\eta) \\
& \theta(\eta)=\frac{\mathrm{T}-\mathrm{T}_{\infty}}{\mathrm{T}_{\omega}-\mathrm{T}_{\infty}}, \theta_{\mathrm{p}}(\eta)=\frac{\mathrm{T}_{\mathrm{p}}-\mathrm{T}_{\infty}}{\mathrm{T}_{\omega}-\mathrm{T}_{\infty}}
\end{aligned}
$$

Where $T-T_{\infty}=A\left(\frac{x}{l}\right)^{2} \theta(\eta)$

Using (13) and (14) in (2) to (12), we obtain the following nonlinear ordinary differential equations

$\frac{\theta_{r}}{\theta-\theta_{r}} \mathrm{f}^{\prime \prime \prime}-\frac{\theta_{r}}{\left(\theta-\theta_{r}\right)^{2}} \mathrm{f}^{\prime \prime} \theta^{\prime}+\mathrm{f} \mathrm{f}^{\prime \prime}-\left[\mathrm{f}^{2}-\mathrm{Gr} \theta+\mathrm{l}^{*} \beta \mathrm{H}[\mathrm{F}-\mathrm{f}]\right]=0$

$G F^{\prime}+F^{2}+\beta[F-f]=0$

$\mathrm{G} \mathrm{G}^{\prime}+\beta[\mathrm{f}+\mathrm{G}]=0$

$\mathrm{HF}+\mathrm{HG}^{\prime}+\mathrm{GH}^{\prime}=0$

$\left(\mathrm{Nr}-\frac{\theta_{k}}{\theta-\theta_{k}}\right) \theta^{\prime \prime}+\frac{\theta_{k}}{\left(\theta-\theta_{k}\right)^{2}} \theta^{\prime 2}+\operatorname{Pr}\left[\left(\mathrm{f} \theta^{\prime}-2 \mathrm{f}^{\prime} \theta\right)+\frac{\mathrm{N}}{\rho \mathrm{c} \tau_{\mathrm{T}}}\left(\theta_{\mathrm{P}}-\theta\right)+\mathrm{N} \mathrm{Ec}\right.$

$\left.\left(\mathrm{F}-\mathrm{f}^{\prime}\right)^{2}-\mathrm{cEc} \frac{\theta_{r}}{\theta-r} f^{\prime \prime 2}\right]=0$,

$2 F \theta_{p}+G \theta_{p}^{\prime}+\frac{c_{p}}{\sigma c_{m} U T}\left[\theta_{\mathrm{p}}-\theta\right]=0$,

where a primce denotes differentiation with respect to $\eta$ and $l^{*}=$ $\frac{m N}{p}, \tau=\frac{m}{K}$ is the relaxation time of the particle phase, $\beta=\frac{1}{c \tau}$ is

the fluid particle interaction parameter, $\mathrm{G}_{\mathrm{r}}=\frac{g \beta^{*}\left(T_{\mathrm{W}}-T_{\infty x}\right)}{c^{2} x}$ is the local Grashof number, $\rho_{r}=\frac{p_{p}}{p}$ is the relative density, $\operatorname{Pr}=\frac{\mu c_{p}}{k^{*}}$ is the Prandt number, $E c=\frac{c l^{2}}{A c_{p}}$ is the Eckert number, $N r=\frac{16 \sigma^{*} T_{m}^{s}}{3 k k^{*}}$ is the Radiation parameter,

$\theta_{r}=\left(\frac{T_{r}-T_{\infty}}{T_{w}-T_{\infty}}\right)$ is viscosity parameter and $\theta_{k}=\left(\frac{T_{k}-T_{\infty}}{T_{w}-T_{\infty}}\right)$ is the thermal conductivity parameter.

The boundary conditions (11) and (12) become

$$
\begin{aligned}
& \mathrm{f}=\mathrm{f}_{0}, \mathrm{f}^{\prime}=1, \theta=1 \text { at } \eta=0, \\
& \mathrm{f}^{\prime}=0, \mathrm{~F}=0, \mathrm{G}=-\mathrm{f}, \mathrm{H}=\omega, \theta \rightarrow 0, \theta_{p} \rightarrow 0 \text { as } \eta \rightarrow \infty
\end{aligned}
$$

where $f_{0}=\frac{v_{w}}{(v c)^{1 / 2 / 2}}$ is the suction parameter.

The physical quantities of interest in this problem are the skin -friction coefficient $c_{f}$ and Nusselt number $N u$ which indicate physically wall shear stress and rate of heat transfer respectively. The wall shear stress $\tau_{w}$ is given by

$$
\tau_{w}=\left[(\mu) \frac{\partial u}{\partial y}\right]_{y=0}=\rho v_{\infty}\left(\frac{\theta_{r}}{\theta_{r^{-}}-1}\right) \sqrt{\frac{U_{0}^{3} \alpha^{2}}{v_{\infty} c_{0}}} f^{\prime \prime}(0)
$$

The skin -friction coefficient $c_{f}$ can be defined as

$$
c_{f}=\frac{2 \tau_{w}}{\rho U_{o}^{2}}=2\left(\frac{\theta_{r}}{\theta_{r}-1}\right) f^{\prime \prime}(0)
$$

The heat transfer from the plate is given by

$$
q_{w}=-k\left[\frac{\partial T}{\partial y}\right]_{y=0}=-k \sqrt{\frac{U_{0} c_{0}}{v_{\infty} \alpha^{2}}} \frac{\left(T_{w}-T_{\infty}\right) \alpha}{U_{0}} \boldsymbol{\theta}^{\prime}(0)
$$

The Nusselt number is given by

$$
N u=\frac{q_{w} U_{0}}{k\left(T_{w}-T_{\infty}\right) \alpha}=-\left(\frac{\theta_{k}}{\theta_{k}-1}\right) \boldsymbol{\theta}^{\prime}(0)
$$

\section{RESULTS AND DISCUSSION}

The equations (15) to (20) together with the boundary conditions (21) and (22) are solved numerically using fourth order Runge-Kutta shooting method. Numerical values are obtained for different values of parameters as shown in graphs and tables for $1=.1, \beta=.51, \omega=0.1, \operatorname{Pr}=1.0, \mathrm{Nr}=3, \mathrm{Ec}=.1$, $\mathrm{fo}=.30, \mathrm{Gr}=.5, \mathrm{~K} 1=.1, \theta_{r}=-10$ and $\theta_{k}=-8$.

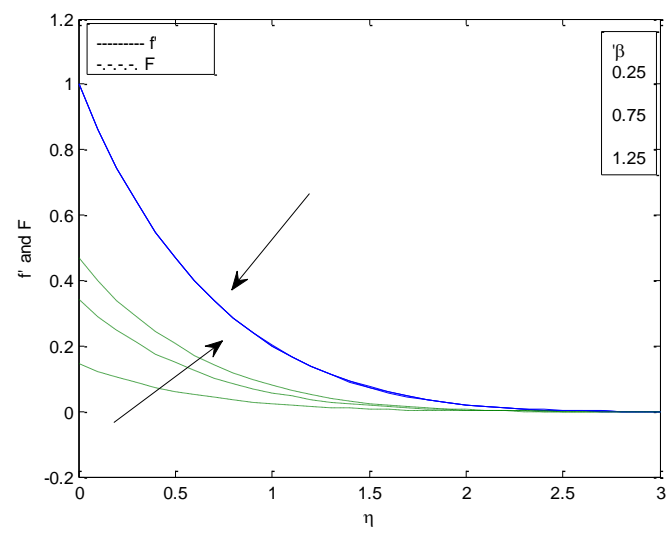

Fig- 1: Velocity profiles for different values of $\beta$.

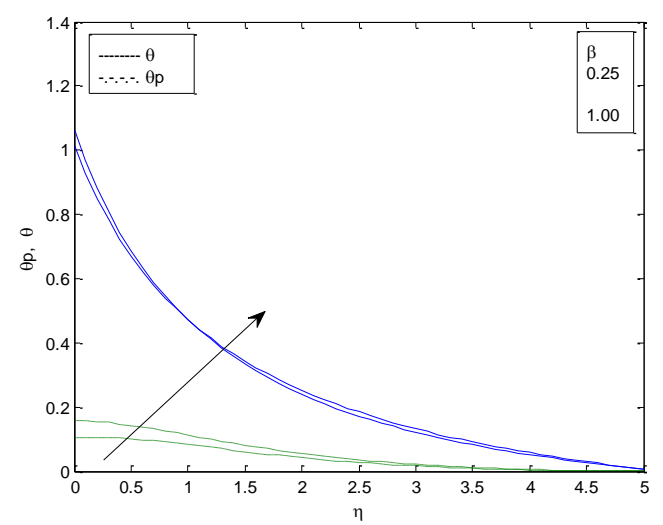

Fig- 2: Temperature profiles for different values of $\beta$.

Fig- 1 and Fig- 2, represent the graphs of velocity and temperature distribution respectively for various values of fluid particle interaction parameter $(\beta)$. It is observed from figures that if $\beta$ increases there is slight decrease in the fluid phase velocity but significant increase in the dust phase velocity. Temperature increase in both 
fluid and dust phase for increasing value of fluid interaction parameter $\beta$.

Figure 3, gives the of velocity profiles for various values of local Grashof number $(G r)$. It is observed that for increasing values of local Grashof number enhence the velocity of both the fluid and dust phases. Physically $G r>0$ means heating of the fluid or cooling of the boundary surface, $G r<0$ means cooling of the fluid or heating of the boundary surface and $G r=0$ corresponds to the absence of free convection current. Figure 4, depicts the effect of local Grashof number $(G r)$ on temperature profiles. It is seen that increasing value of $\mathrm{Gr}$ results in thinning of the thermal boundary layer associated with an increase in the wall temperature gradient and hence produces an increase in the heat transfer rate.

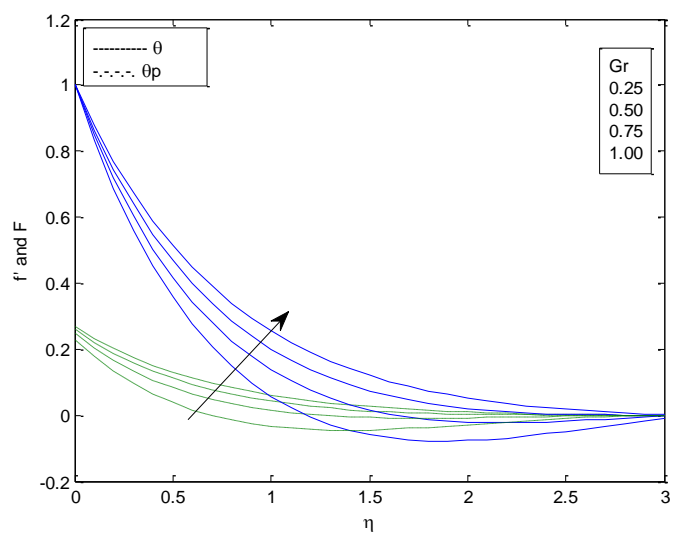

Fig- 3: Velocity profiles for different values of $G r$

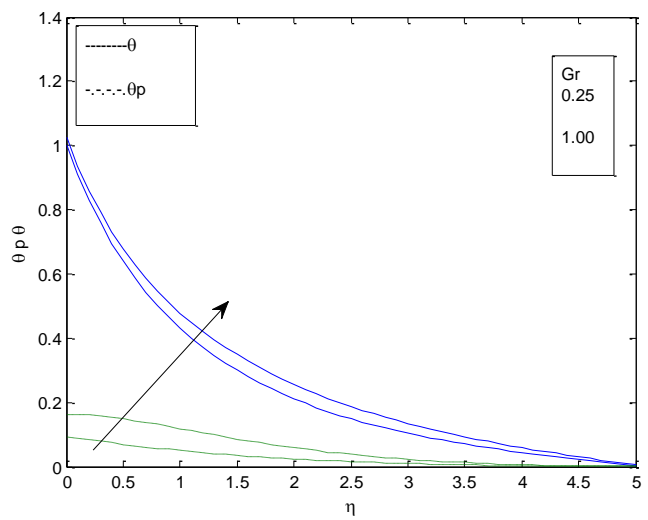

Fig- 4: Temperature profiles for different values of $G r$.

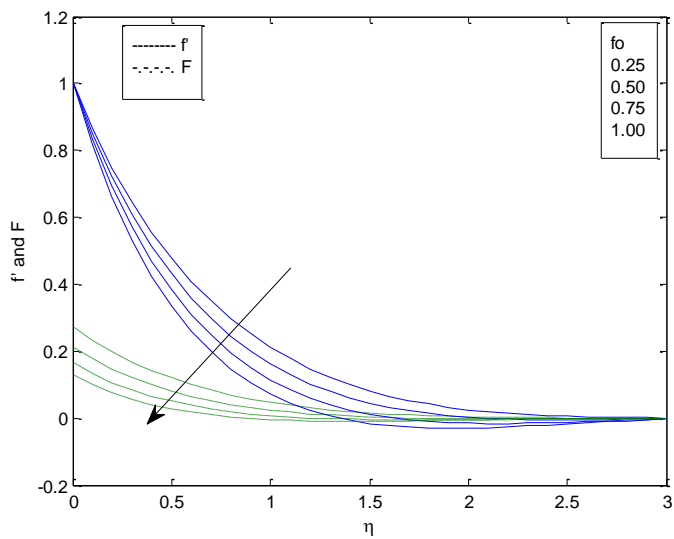

Fig- 5: Velocity profiles for different values of $f(0$.

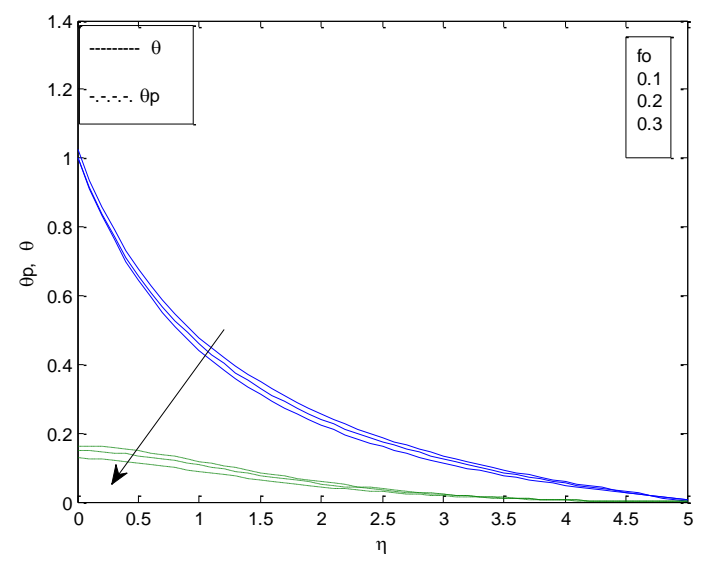

Fig- 6: Temperature profiles for different values of $f 0$

Fig- 5, shows the effect of suction parameter $f_{o}$ on the velocity profiles. It is observed that both fluid and dust phase velocity profiles tends asymptotically to zero. The velocity profiles decreases as suction parameter $f_{0}$ increases. It is seen from the Fig- 6 that the fluid and dust phase temperature profiles decrease monotonically for increase of suction.

Figure 7, displays the variations of dimensionless temperature profile $\boldsymbol{\theta}(\eta)$ with the variation of dimensionless reference temperature corresponding to Prandtl number $P_{r}$. It is observed from the figure -7 that temperature increases with the increasing values of $P_{r}$.It is due to the reason that with the increasing values of the Prandtl number the thermal diffusivity of the fluid will be decreases and as a result thermal conductivity will be decreases. Therefore the volumetric heat capacity of the fluid becomes larger. Velocity distribution for various values of $\mathrm{Pr}$ is plotted in figure 8. It is observed that for increasing values of Prandtl number $\mathrm{Pr}$ retarded the velocity for both the fluid phase as well as dust phase. It is seen from all the figures that the fluid phase is almost parallel to the dust phase and velocity and temperature in the fluid phase is higher than that of the dust phase.

The temperature profiles $\theta(\eta)$ ) and $\theta_{p}(\eta)$ are plotted for different values of radiation parameter $\mathrm{Nr}$ in Fig- 9 and Fig- 15. It is observed that the increase in the thermal radiation parameter $\mathrm{Nr}$ enhance temperature significantly.

Velocity profile for the variable viscosity parameter $\theta_{r}$ are presented in figures 10 and 14 . It is seen that velocity decreases with viscosity due to increase of friction.

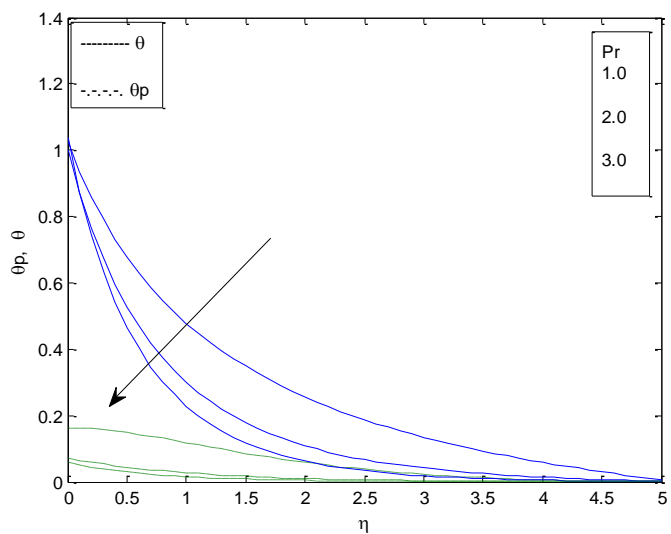

Fig- 7: Temperature profiles for different values of $P r$. 


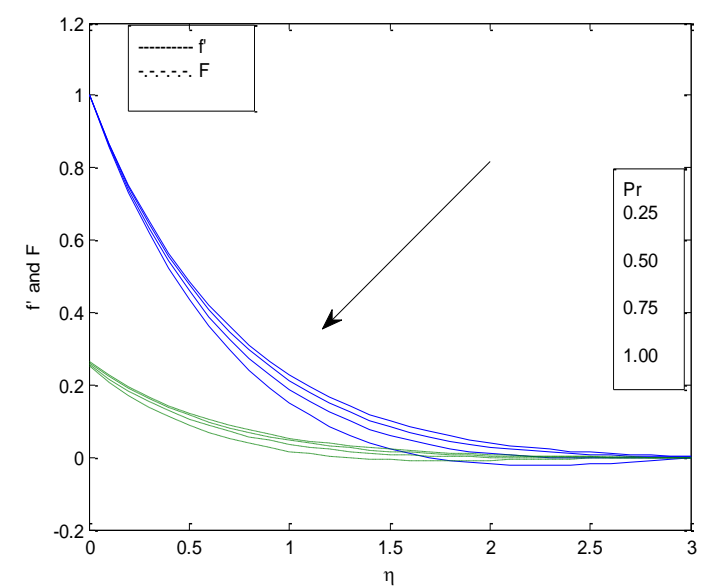

Fig- 8: Velocity profiles for different values of $P$.

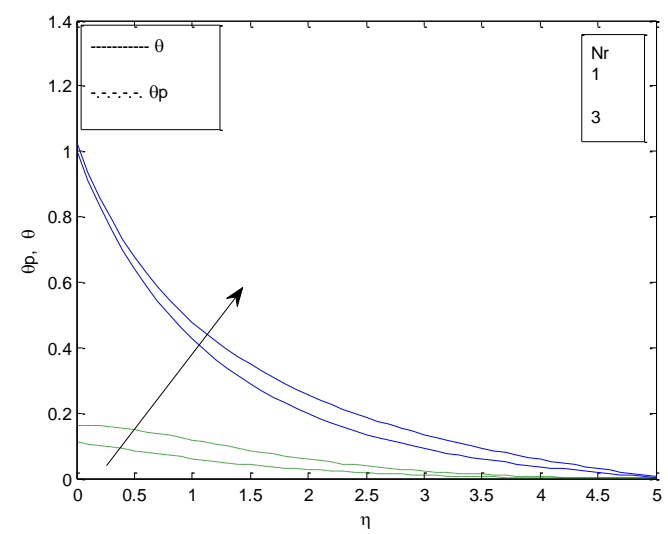

Fig- 9: Temperature profiles for different values of $N$.

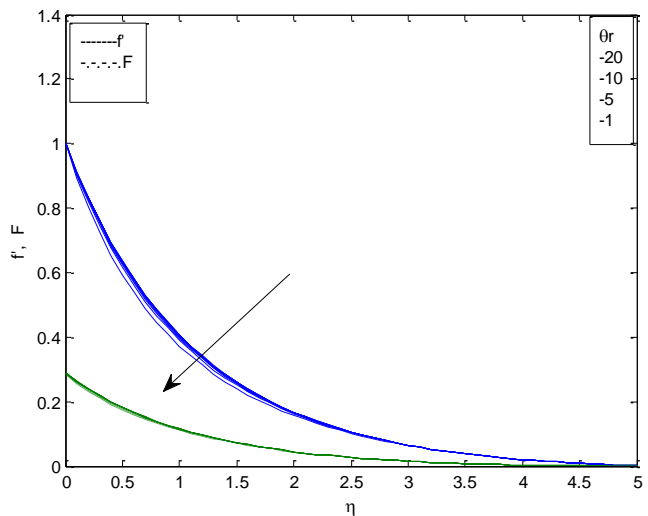

Fig- 10: Velocity profiles for different values of $\theta$.

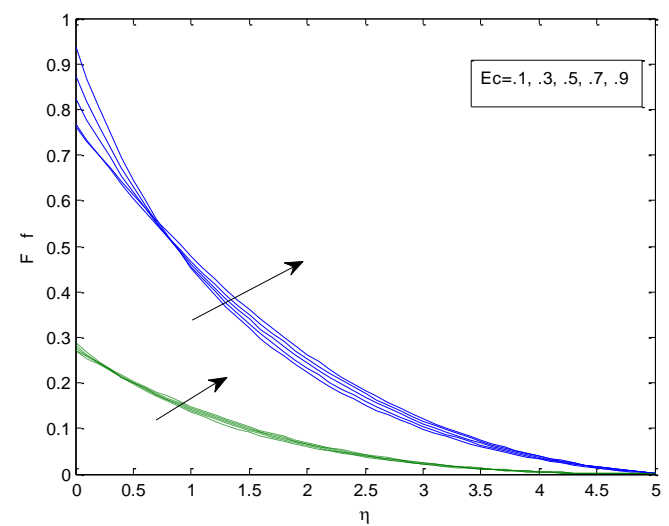

Fig- 11: Velocity profiles for different values of $E c$

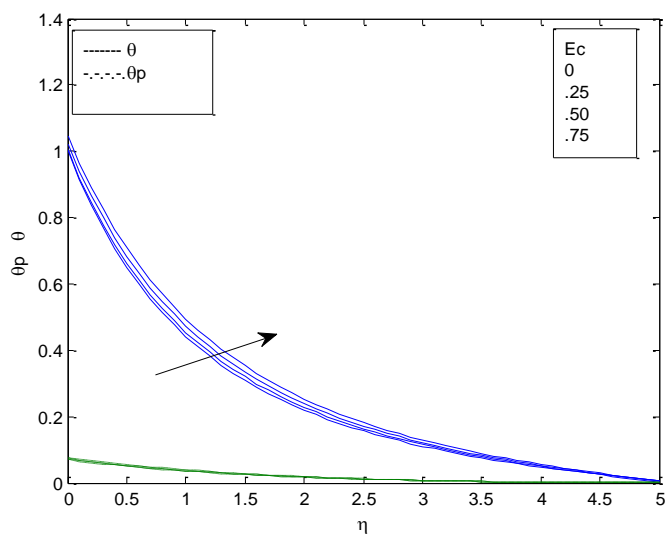

Fig- 12: Temperature profiles for different values of $E c$.

The velocity and temperature profiles for different values of Eckert number Ec is presented in figures 11 and 12. The Eckert number show no significant effects on the velocity profiles where as it enhances the temperature due to dissipation.

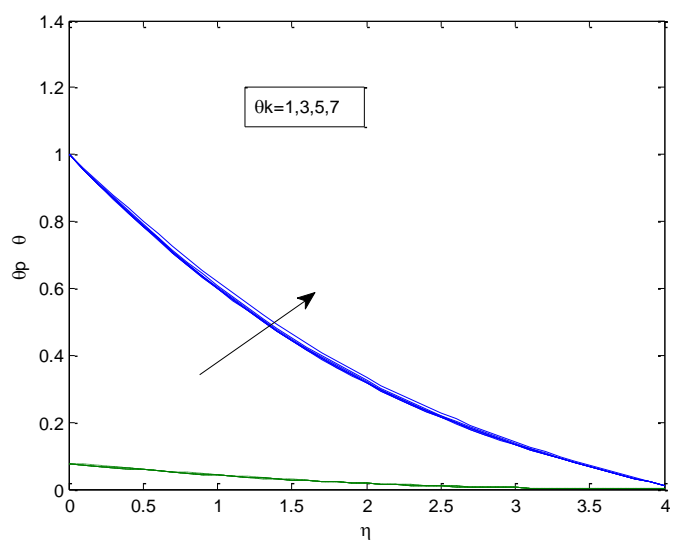

Fig- 13: Temperature profiles for different values of $\theta_{k}$ 


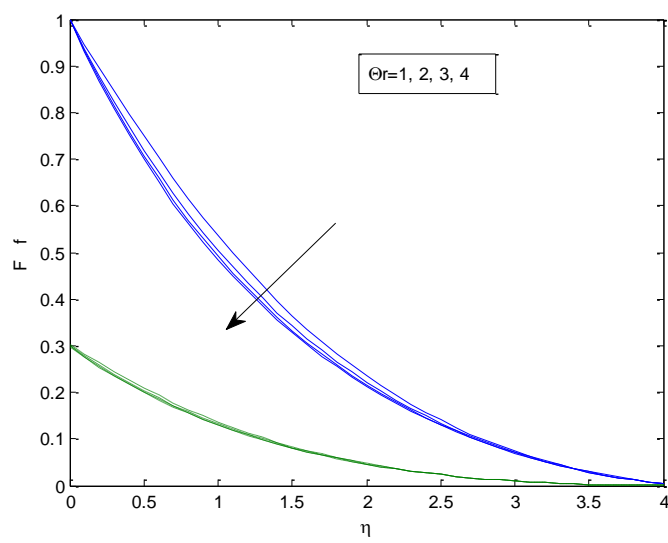

Fig- 14: Velocity profiles for different values of $\theta_{r}$

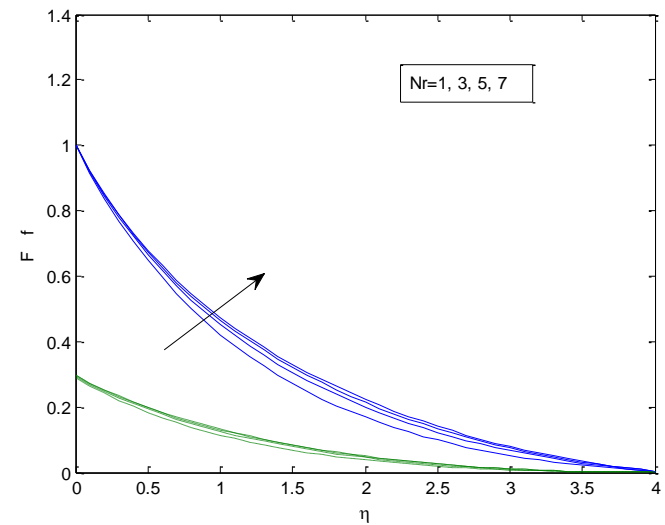

Fig- 15: Velocity profiles for different values of $\mathrm{Nr}$

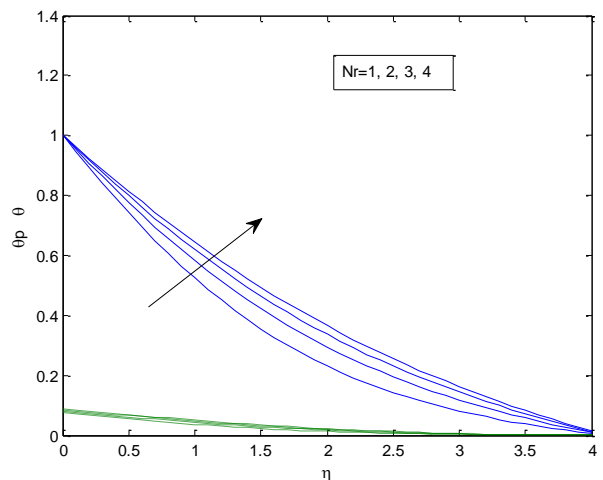

Fig- 16: Temperature profiles for different values of $\mathrm{Nr}$

Figures (13) and (16) display the variations of dimensionless temperature profiles with the variation of dimensionless reference temperature corresponding to thermal conductivity parameter $\theta_{k}$, and radiation parameter Nr. From figure (13) it is observed that temperature slightly increases when $\theta_{k}$ increases. It is due to the fact that the kinematic viscosity of the fluid increases with the increase of $\theta_{k}$ and as a result temperature increases. It is observed from the figure (16) that temperature increases with the increasing values of $\mathrm{Nr}$. It is due to the radiative heat transfer the thermal diffusivity of the fluid increases and as a result thermal conductivity increases as a result temperature increases.

Finally the skin friction coefficient $C_{f}$ which gives the wall shear stress and Nusselt number $N u$ which gives the rate of heat transfer are shown in the tables (1) - (4) for different values of $\mathrm{Nr}$, and $\operatorname{Pr}$ against $\theta_{r}$ and $\theta_{k}$ and for $\mathrm{l}=.1, \beta=.51$, $\omega=0.1, \mathrm{Pr}=1$., $\mathrm{Nr}=3, \mathrm{Ec}=.1$, fo=.30, $\mathrm{Gr}=.5$ and $\mathrm{K} 1=.1$. The behaviour of these parameters is self evident from the tables and hence any further discussions about them seem to be redundant.

Values of skin friction coefficient $\mathrm{C}_{\mathrm{f}}$ and Nusselt number $\mathrm{Nu}$

Table-1

$\mathrm{Nr} \rightarrow$
\begin{tabular}{|c|c|c|c|c|c|c|}
\hline $\begin{array}{c}\theta \mathrm{k} \\
\downarrow\end{array}$ & $\mathrm{Cf}$ & $\mathrm{Nu}$ & $\mathrm{Cf}$ & $\mathrm{Nu}$ & $\mathrm{Cf}$ & $\mathrm{Nu}$ \\
\hline 2 & -0.0206 & -0.0617 & -0.0254 & -0.0931 & -0.0292 & -0.1208 \\
\hline 3 & -0.0198 & -0.0441 & -0.0248 & -0.0673 & -0.0286 & -0.0881 \\
\hline 4 & -0.0195 & -0.0384 & -0.0245 & -0.059 & -0.0284 & -0.0773 \\
\hline 5 & -0.0194 & -0.0356 & -0.0243 & -0.0548 & -0.0283 & -0.072 \\
\hline
\end{tabular}

Table-2

$\mathrm{Nr} \rightarrow \quad 2.0 \quad 3.0 \quad 4.0$

\begin{tabular}{|c|c|c|c|c|c|c|}
\hline $\begin{array}{c}\theta \mathrm{k} \\
\downarrow\end{array}$ & $\mathrm{Cf}$ & $\mathrm{Nu}$ & $\mathrm{Cf}$ & $\mathrm{Nu}$ & $\mathrm{Cf}$ & $\mathrm{Nu}$ \\
\hline-6 & -0.01 & -0.0686 & -0.0121 & -0.1018 & -0.0138 & -0.1311 \\
\hline-4 & -0.0094 & -0.0693 & -0.0114 & -0.1026 & -0.0129 & -0.1318 \\
\hline-2 & -0.008 & -0.0711 & -0.0096 & -0.1049 & -0.0118 & -0.1307 \\
\hline
\end{tabular}

Table-3
$\mathrm{Pr} \rightarrow 0.75$
1.00
1.75

\begin{tabular}{|c|c|c|c|c|c|c|}
\hline $\begin{array}{c}\boldsymbol{\theta k} \\
\downarrow\end{array}$ & $\mathbf{C f}$ & $\mathbf{N u}$ & $\mathbf{C f}$ & $\mathbf{N u}$ & $\mathbf{C f}$ & $\mathbf{N u}$ \\
\hline 2 & -0.0244 & -0.0851 & -0.0203 & -0.0553 & -0.02 & -0.0357 \\
\hline 3 & -0.0237 & -0.0615 & -0.0194 & -0.0397 & -0.0165 & -0.0262 \\
\hline 4 & -0.0234 & -0.0538 & -0.0191 & -0.0347 & -0.0161 & -0.0228 \\
\hline 5 & -0.0233 & -0.05 & -0.019 & -0.0322 & -0.0159 & -0.0211 \\
\hline
\end{tabular}

Table-4
$\operatorname{Pr} \rightarrow 1.0$
1.25
1.50
2.0

\begin{tabular}{|c|c|c|c|c|c|c|c|c|}
\hline $\begin{array}{c}\text { Or } \\
\downarrow\end{array}$ & $\mathbf{C}_{\mathrm{f}}$ & $\mathbf{N u}$ & $\mathbf{C}_{\mathrm{f}}$ & $\mathbf{N u}$ & $\mathbf{C}_{\mathrm{f}}$ & $\mathbf{N u}$ & $\mathbf{C}_{\mathrm{f}}$ & $\mathbf{N u}$ \\
\hline-8 & -0.0097 & -0.0612 & -0.0081 & -0.0411 & -0.0069 & -0.0281 & -0.006 & -0.0195 \\
\hline-6 & -0.0095 & -0.0615 & -0.0079 & -0.0414 & -0.0067 & -0.0283 & -0.0059 & -0.0196 \\
\hline-4 & -0.0089 & -0.0621 & -0.0075 & -0.0419 & -0.0064 & -0.0287 & -0.0055 & -0.0199 \\
\hline-2 & -0.0076 & -0.0637 & -0.0064 & -0.0432 & -0.0055 & -0.0298 & -0.0051 & -0.2011 \\
\hline
\end{tabular}




\section{CONCLUSIONS}

The effect of variable viscosity and thermal conductivity together with thermal radiation on flow and heat transfer of a dusty fluid over a vertical permeable stretching sheet is studied numerically. Velocity and temperature profiles are presented graphically. Influence of all the physical parameters found to effect the flow and heat transfer characteristics. The fluid particle interaction parameter $\beta$, local Grashof number, suction parameter, radiation parameter, Prandtl number, Eckert number, viscosity parameter $\theta_{r}$ and thermal conductivity parameter $\theta_{\mathrm{k}}$ are considered for discussion. We may conclude as follows:

1. Velocity of fluid phase decreases and dust phase increases as $\beta$ increases.

2. Velocity of fluid, dust phase increases and temperature of fluid and dust phase decreases as $G r$ increases.

3. Velocity and temperature of both fluid and dust phase decreases as $\operatorname{Pr}$ and $f_{\mathrm{O}}$ increases.

4. Temperature increases for increasing value of the radiation parameter $\mathrm{Nr}$ and Eckert number Ec.

5. Viscosity parameter $\theta_{r}$ decreases the fluid and dust phase velocity.

6. Thermal conductivity $\theta_{\mathrm{k}}$ enhances the temperature.

7. Wall shear stress as well as the heat transfer rate increase with increase of viscosity, thermal conductivity and thermal radiation.

8. Wall shear stress as well as the heat transfer rate both decrease with increase of thermal conductivity and Prandtl number but increase for increase of viscosity parameter and Prandtl number.

\section{REFERENCES}

[1] L. J. Crane. Flow past a stretching sheet, Z. Angew. Math. Phys., 21(1970): 645-647.

[2] L. J. Grubka and K. M. Bobba. Heat transfer characteristics of a continuous stretching surface with variable temperature, J. Heat Transfer., 107(1985): 248250 .

[3] J. E. Daskalakis. Free Convection Effects in the Boundary Layer Along a Vertically Stretching Flat Surface, Canadian Journal of Physics., 70(1993): 12531260 .

[4] C. H. Chen. Laminar Mixed Convection Adjacent to Vertical, Continuously Stretching Sheets, Heat and Mass Trans-fer., 33(1998): 471-476.

[5] A. J. Chamkha. Hydromagnetic Three-Dimensional Free Convection on a Vertical Stretching Surface with Heat Generation or Absorption, Int. J. of Heat and Fluid Flow., 20(1)(1999): 84-92.

[6] A. Ishak, R. Nazar and I. Pop. Boundary layer flow and heat transfer over an unsteady stretching vertical surface, Meccanica., 44(2009): 369375.
[7] Saleh M Alharbi, Mohamed A A Bazid and Mahmoud $\mathrm{S}$ El Gendy. Flow and natural convection heat transfer in a power law fluid past a vertical plate with heat generation, Applied Mathematics., 1(2010): 446-455.

[8] B. J. Gireesha, G. K. Ramesh, H. J. Lokesh and C. S. Bagewadi. Boundary Layer Flow and Heat Transfer of a Dusty Fluid over a Stretching Vertical Surface, Applied Mathematics., 2(4)(2011): 475-481.

[9] M. Kumari, A. Slaouti, H.S. Takhar, S. Nakamura and G. Nath. Unsteady Free Convection Flow over a Continuous Moving Vertical Surface, Acta Mechanica., 116(1-4)(1996): 75-82.

[10] K. M. Chakrabarti, Note on Boundary layer in a dusty gas, AIAA Journal., 12(8)(1974) 1136-1137.

[11] N. Datta and S. K. Mishra. Boundary Layer Flow of a Dusty Fluid over a Semi-Infinite Flat Plate, Acta Mechanica.42(1982): 71-83.

[12] V. M. Agranat. Effect of pressure gradient on friction and heat transfer in a dusty boundary layer, Fluid Dynamics.23(5)(1988): 729-732.

[13] K. Vajravelu and J. Nayfeh. Hydromagnetic flow of a dusty fluid over a stretching sheet, Int. J. of Non-linear Mechanics., 27(1992): 937-945.

[14] Evgeny S Asmolov and Sergei V Manuilovich. Stability of a dusty gas laminar boundary layer on a flat plate, $J$. ofFluid Mechanics., 365(1998): 137-170.

[15] XIE Ming-liang, LIN Jian-zhong and XING Fu-tang. On the hydrodynamic stability of a particle-laden flow in growing flat plate boundary layer., $J$. of Zhejiang University SCIENCE A, 8(2)(2007): 275-284.

[16] G. Palani and P. Ganesan. Heat transfer effects on dusty gas flow past a semi-infinite inclined plate. Forsch Ingenieurwes., 71(2007): 223-230.

[17] B. J. Gireesha, G. K. Ramesh, M. Subhas Abel and C. S. Bagewadi. Boundary layer flow and Heat Transfer of a Dusty Fluid Flow over a Stretching Sheet with Nonuniform heat Source/Sink., Int. J. of Multiphase Flow, 37(2011): 977-982.

[18] C. H. Chen. MHD mixed convection of a power law fluid past a strtching surface in the presence of thermal radiation and internal heat generation/absorption, Int. J. of Nonlinear Mechanics., 44(2008): 296-303.

[19] S. Mukhopadhyay and G. C. Layek. Effects of thermal radiation and variable fluid viscosity on free convective flow and heat transfer past a porous stretching surface, Int. J. Heat Mass Transfer., 51(2008): 2167-2178.

[20] G.K. Ramesh , B.J. Gireesha and C.S.Bagawedi Convetive Heat Transfer in a Dusty Fluid over a Vertical Permeable Surface with Thermal Radiation, Int, J, Nonlinear Mechanics, Vol. 14(2012),No. 2, 243-250.

[21] Lai F.C. and Kulacki F.A., The effect of variable viscosity on convective heat and mass transfer along a vertical surface in saturated porous medium, Int. J. Heat and Mass Transfer 33, 1028-1031 